
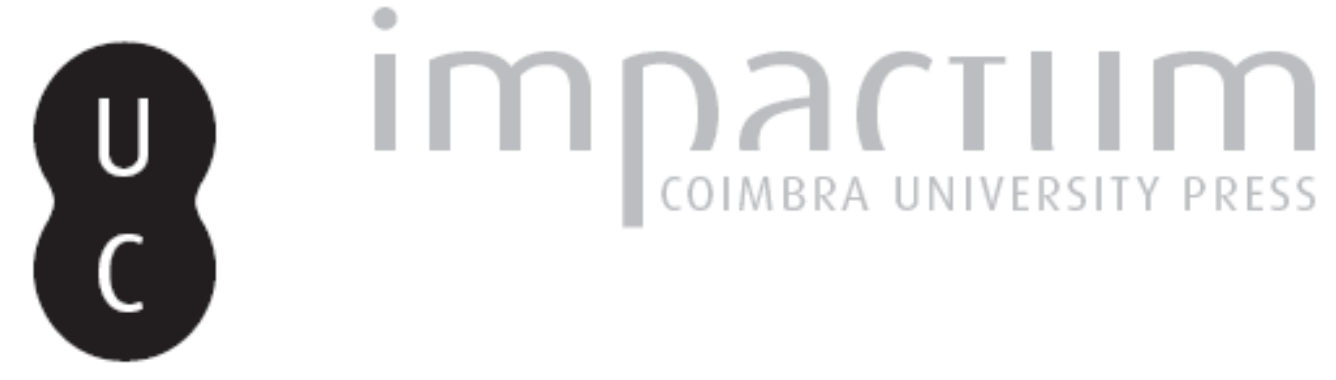

\title{
O processo de implementação da política de coesão europeia em Portugal: o avanço do diálogo político-democrático e as nuances da governação multinível assimétrica
}

\author{
Autor(es): $\quad$ Castro, Aline Contti
}
Publicado por: $\quad$ Centro de Informação Europe Direct de Aveiro; Centro de Estudos Interdisciplinares do Século XX

URL

persistente:

URI:http://hdl.handle.net/10316.2/37108

DOI:

DOI:http://dx.doi.org/10.14195/1647-6336_12_3

Accessed : $\quad$ 26-Apr-2023 08:13:02

A navegação consulta e descarregamento dos títulos inseridos nas Bibliotecas Digitais UC Digitalis, UC Pombalina e UC Impactum, pressupõem a aceitação plena e sem reservas dos Termos e Condições de Uso destas Bibliotecas Digitais, disponíveis em https://digitalis.uc.pt/pt-pt/termos.

Conforme exposto nos referidos Termos e Condições de Uso, o descarregamento de títulos de acesso restrito requer uma licença válida de autorização devendo o utilizador aceder ao(s) documento(s) a partir de um endereço de IP da instituição detentora da supramencionada licença.

Ao utilizador é apenas permitido o descarregamento para uso pessoal, pelo que o emprego do(s) título(s) descarregado(s) para outro fim, designadamente comercial, carece de autorização do respetivo autor ou editor da obra.

Na medida em que todas as obras da UC Digitalis se encontram protegidas pelo Código do Direito de Autor e Direitos Conexos e demais legislação aplicável, toda a cópia, parcial ou total, deste documento, nos casos em que é legalmente admitida, deverá conter ou fazer-se acompanhar por este aviso.

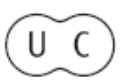


DEBATER

A EUROPA

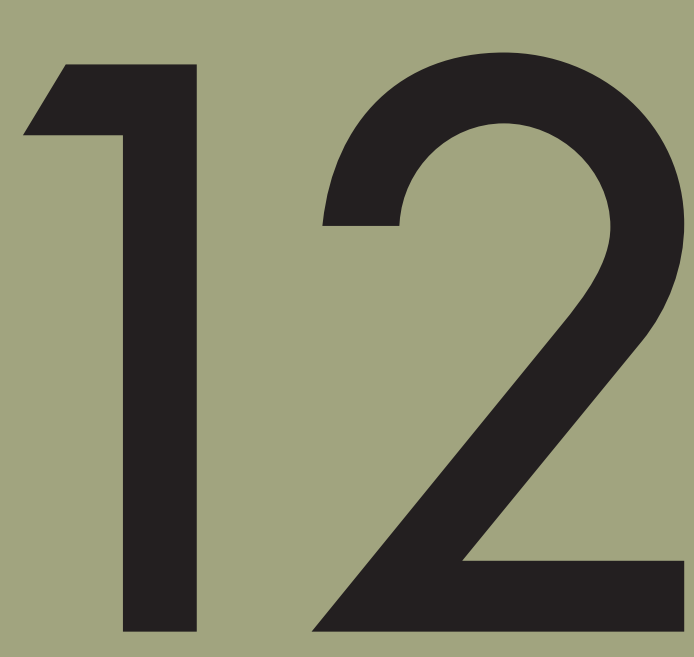

jan-jun 2015

POLITICAS REGIONAIS DA UE

EU REGIONAL POLICIES 


\title{
O PROCESSO DE IMPLEMENTAÇÃO DA POLÍTICA DE COESÃO EUROPEIA EM PORTUGAL: O AVANÇO DO DIÁLOGO POLÍTICO-DEMOCRÁTICO E AS NUANCES DA GOVERNAÇÃO MULTINÍVEL ASSIMÉTRICA
}

\author{
Aline Contti Castro \\ Professora Departamento de Relações Internacionais \\ Universidade Federal da Paraíba (UFPB)-Brasil \\ E-mail: castroalinec@gmail.com
}

\begin{abstract}
The EU's Economic, Social and Territorial Cohesion Policy accounts for about a third of the its budget of the block and has been designed in order to cause socioeconomic and political impacts the increase of democratic participation at the community level. The objective of this study is to analyze the influence of European cohesion policy with regard to the evolution of Multilevel Governance in Portugal and in its regions. More specifically, it seeks to analyze the performance and the interrelationship between the various actors involved in the implementation process (EUDG-Regio, Central Government, sub-national authorities and civil society), their level of participation and the differences between portuguese continental and autonomous regions. It highlights advances and difficulties in the implementation process - in the context of what has been conceptualized as an asymmetric multilevel governance.
\end{abstract}

Keywords: European Union; Economic, Social and Territorial Cohesion Policy; implementation; Portugal; regions; asymmetric multilevel governance.

\section{Resumo}

A Política de Coesão Econômica, Social e Territorial (PCEST) da UE responde por cerca de um terço do orçamento do bloco e foi desenhada no sentido de causar impactos socioeconômicos e 
políticos - aumento da participação democrática no âmbito comunitário. O objetivo do presente trabalho é analisar a influência da política de coesão europeia no tocante à evolução da Governação Multinível em Portugal e em suas regiões. Mais especificamente, procura-se analisar a atuação e a inter-relação entre os diversos atores envolvidos no processo de implementação (UE-DG-Regio, Governo Central, autoridades subnacionais e sociedade civil), seu grau de participação e as diferenças entre as regiões continentais e autônomas portuguesas. São destacados avanços e dificuldades do processo de implementação - no contexto do que foi conceituado como um processo de governança multinível assimétrica.

Palavras-chave: União Europeia; Política de Coesão Econômica, Social e Territorial; implementação; Portugal; regiões; governação multinível assimétrica.

\section{Introdução}

Alguns "sustentam que o nome do jogo na Europa é 'governação multinível'. Demandas pelo aprimoramento da democracia participativa em todos os níveis de governação estão associadas com controvérsias sobre a extensão da subsidiariedade ou da centralização, permitindo, assim, à Europa uma diversidade de ritmos, compromissos assimétricos com as instituições centrais e tomadas de decisão mais descentralizadas. Nem o Neofuncionalismo nem Jean Monnet imaginaram esses refinamentos." 1

A Política de Coesão Econômica, Social e Territorial (PCEST) da UE responde por cerca de um terço do orçamento do bloco e representa a política internacional mais avançada na área de diminuição de assimetrias. ${ }^{2}$ Esta foi desenhada no sentido de causar impactos socioeconômicos entre eles, redução das disparidades regionais e convergência do PIB per capita das regiões para a

\footnotetext{
1 HAAS, Ernst B. Does Constructivism subsume neo-functionalism? In: CHRISTIANSEN, Thomas. Social Construction of Europe. UK: Sage Publications (2001). Livre tradução da autora. They "maintain that the name of the game in Europe is 'multi-level governance' Demands for the improvement of participatory democracy at all levels of governance go hand in hand with controversy over the extent of subsidiarity, or of centralization, thus allowing for Europe a plusieurs vitesses, asymmetrical commitments to central institutions and more decentralized decision-making. Neither NF [neo-functionalism] nor Jean Monnet imagined these refinements."

${ }^{2}$ Este artigo é parte da tese de Doutoramento defendida no Instituto de Relações Internacionais (IREL) da Universidade de Brasília (UnB) em parceria com o Instituto Superior de Ciências Sociais e Políticas (ISCSP) da Universidade de Lisboa (UL). Agradecimentos à CAPES que concedeu a bolsa necessária à realização da pesquisa em Portugal; assim como à valiosa contribuição dos seguintes entrevistados: Prof ${ }^{a}$ Arminda Neves (UL), Prof. Dr. Eduardo Brito Henriques (Presidente da CCDR-LVT), Sr. Paulo Areosa Feio (Coordenador do Observatório do QREN), Sr ${ }^{\mathrm{a}}$ Alexandra Rodrigues (Diretora de Desenvolvimento Regional da CCDR-Centro), Sr. Mario Neves (Diretor de Desenvolvimento Regional da CCDR-Norte), Dras. Maria João Botelho e Rita Brito (MNE - DG de Assuntos Europeus), Sr. Luiz Sá Pessoa (Chefe da Representação da Comissão Europeia em Portugal) e Sra. Judit Torokne Rozsa (Representante da Comissão Europeia, DG-Regio, relativa à Portugal). Tendo em vista a escassa literatura sobre o processo de implementação, a maior parte das fontes deste artigo foram as entrevistas (semiestruturadas) realizadas em Portugal, no início de 2014.
} 
média europeia - e políticos - aumento da participação democrática no âmbito comunitário, tendo em vista o debate sobre o défice democrático das instituições europeias.

O conceito de governação refere-se aos modos de prover bens comuns ou estabelecer a ordem pública que resulta da interação entre atores variados e de formas de coordenação de seus comportamentos ${ }^{3}$.Tal conceito é utilizado de forma ampla na literatura. Assim, a Comissão Europeia (CE) acabou por estabelecer seu próprio conceito em 2001, no documento referido como o Livro Branco sobre a Governança Europeia ${ }^{4}$ : o termo governação europeia então refere-se a regras, processos e comportamentos que afetam a maneira como o poder é exercido em nível europeu, particularmente no que se refere à abertura, participação, responsabilização (accountability), efetividade e coerência. No tocante à participação política, segundo a Comissão Europeia, o objetivo é trazer a União para mais próximo dos cidadãos europeus, torná-la mais efetiva, reforçar a democracia na Europa e consolidar a legitimidade de suas instituições. Esta nova forma de governação deve se basear na estruturação e implementação de políticas melhores e mais consistentes, associando as organizações da sociedade civil e as instituições europeias. Tal aprimoramento deve envolver também reformas na legislação comunitária, tornando-a mais clara e efetiva. Assim, em relação aos Fundos Estruturais, a Comissão procurou estimular os Estados-nação com tradição centralizadora, como Portugal, a favorecer a participação política de entidades subnacionais. Ademais, reformas foram feitas no intuito de desburocratizar o funcionamento de tal política. Em relação especificamente à política estrutural, Gary Marks desenvolveu o conceito de governação multinível (GMN) e a caracterizou como um sistema de negociações contínuas entre governos em vários níveis territoriais ${ }^{5}$.

Neste contexto, o presente trabalho tem como objetivo geral analisar a influência da política de coesão europeia no tocante à evolução da GMN em Portugal e em suas regiões ${ }^{6}$. Em suma, pretende-se destacar os avanços e recuos incitados pela política de coesão em Portugal. De forma específica, os objetivos são os seguintes: avaliar o processo de implementação da política de coesão em Portugal; analisar a atuação e a inter-relação entre os diversos atores na implementação da PCEST em Portugal, em especial a UE, o governo central, as autoridades subnacionais e a sociedade civil; verificar o grau de participação dos atores relevantes no processo de

\footnotetext{
${ }^{3}$ ROSENAU, James N. Governance, Order and Change in World Politics. In: ROSENAU, James N.; CZEMPIEL, Ernst, O. (ed.), Governance without Government. Order and Change in World Politics. Cambridge; Cambridge University Press (1992) p. 1-29.

${ }^{4}$ C.E. Comissão Europeia. Livro Branco sobre a Governança Europeia. Bruxelas: Comissão Europeia, 2001.

${ }^{5}$ MARKS, Gary. Structural Policy and Multilevel Governance in the EC. In: CAFRUNY, Alan and ROSENTHAL, Glenda (eds.). The State of the European Community. Boulder: Lynne Rienner, 1993.

${ }^{6}$ As regiões portuguesas NUTS 2 são: Norte, Centro, Lisboa, Alentejo, Algarve, e as duas regiões autônomas dos Açores e da Madeira. NUTS significa Nomenclatura das Unidades Territoriais para fins Estatísticos.
} 
implementação; e destacar as diferenças no processo de implementação entre as regiões continentais e autônomas portuguesas. A trajetória da pesquisa reforça a importância da análise do caso português, pouco abordado pela literatura.

O aprimoramento da governação europeia representa o caminho fundamental na busca de minorar problemas relativos ao défice democrático da UE, com primazia da governação multinível, cuja literatura apresenta eixos de análise e hipóteses que informam a presente análise empírica. Nesse sentido, Piattoni ${ }^{7}$ desenvolve e explica algumas hipóteses a serem testadas e (eventualmente) confirmadas: i) as regiões devem se mobilizar em nível da UE (politics - mobilização); ii) a política de coesão deve estimular um maior ativismo por parte de coalizões de defesa (advocacy) transregional público-privadas em nível da UE (policy - ativismo político); iii) como consequência dessas variadas mobilizações, as regiões devem ser induzidas pela política de coesão a conectaremse mais intimamente com as respectivas sociedades civis (polity - mudança estrutural); iv) finalmente, por meio da política de coesão, as regiões devem ser empoderadas vis-à-vis seus governos centrais.

Marks ${ }^{8}$ agrega a hipótese de que a maior dependência dos países da coesão (da UE-15) dos recursos europeus resultaria em uma maior influência da Comissão nestes países em termos de programação; e acrescenta ainda outra variável relativa à institucionalização de redes de políticas territoriais e sua força normativa. A hipótese do autor é de que a Comissão (assim como outros agentes externos) pode ser mais influente quando as redes forem pouco institucionalizadas. De acordo com essas inferências, podemos afirmar que a dependência dos recursos europeus contribui para a profunda adesão portuguesa a este projeto; e a baixa institucionalização amplia as possibilidades de influência da Comissão. Parâmetros a serem testados na abordagem empírica.

$\mathrm{O}$ artigo procura testar tais hipóteses, destaca o avanço do diálogo político-democrático e conceitua originalmente as relações entre a Comissão Europeia e o Governo Português como uma dinâmica de competências parcialmente partilhadas no contexto mais amplo do que podemos definir como um processo de GMN assimétrica. De forma geral, parte-se da hipótese de que a PCEST representou um importante estímulo para Portugal e suas regiões em termos de avanço político-administrativo. A política regional do país foi em grande parte desenvolvida para atender aos imperativos da dinâmica da coesão. O exercício de planejamento estratégico regional tornou-se então prática regular. Contudo, o pressuposto do Estado unitário dificultou o avanço e legitimação

\footnotetext{
${ }^{7}$ PIATTONI, Simona. The theory of multi-level governance: conceptual, empirical and normative challenges. Oxford: Oxford University Press, 2010.

${ }^{8}$ MARKS, Gary. Exploring and Explaining Variation in EU Cohesion Policy. In: HOOGHE, Liesbet (ed). Cohesion Policy and European Integration: Building Multilevel Governance. Oxford: Oxford University Press, (1996), p. 388422.
} 
deste processo em nível regional. Exceção deve ser feita às Regiões Autônomas (RAs) que gradativamente tornaram-se mais atuantes neste âmbito. Ainda assim, a participação das subunidades portuguesas na política europeia parece reduzida, por exemplo, não há escritório de representação das regiões portuguesas em Bruxelas. Finalmente, a última parte do trabalho destaca os avanços e dificuldades mais evidentes no tocante à implementação da PCEST em Portugal.

\section{As relações entre a Comissão Europeia e Portugal no âmbito da Política de Coesão: competências parcialmente partilhadas}

O grande debate sobre as relações e poderes relativos da Comissão Europeia e dos Estados membros na política regional esteve fundamentado nas divergências entre intergovernamentalistas e defensores da GMN. Em geral, ao se analisar as reformas dos Fundos Estruturais e o jogo de poder entre os atores nacionais e supranacionais neste âmbito, a literatura tende a reforçar a visão de que a influência da Comissão foi muito significativa entre 1988 e 1993 e que, a partir de então, os Estados voltaram a controlar os mecanismos da política estrutural. A tese da renacionalização é defendida por autores relacionados à Escola Intergovernamental.

Outros autores, no entanto, ligados à perspectiva da GMN procuraram questionar tal tese. Para Gary Marks ${ }^{9}$, o poder foi dividido entre os atores supranacionais, nacionais e subnacionais. Bachtler e Mendez ${ }^{10}$ aprofundaram o debate e justificaram que a interpretação estadocêntrica esteve muito focada nas análises dos Regulamentos da Política de Coesão, com a avaliação inadequada do processo de implementação e a apresentação, assim, de argumentos falhos. Nesta visão, as reformas de 1993, 1999 e 2006, conhecidas na literatura por evidenciarem o fortalecimento do poder dos Estados, mostraram entretanto a continuidade da influência comunitária em pontos chaves do processo de implementação política.

No caso de Portugal, todos os entrevistados ressaltaram as ótimas relações entre a Comissão (DG-Regio) e o Governo português, em nível politico e em nível de trabalho (com os parceiros da Comissão no Governo), e a continuidade desta dinâmica ao longo dos diversos períodos de programação.

Portugal construiu uma imagem muito positiva no contexto europeu, a imagem do bom aluno, que se esforça em fazer as coisas corretamente. Nas visões da Comissão e do MNE (Ministério dos Negócios Estrangeiros), o processo de construção de confiança está consolidado, há

\footnotetext{
${ }^{9}$ Idem, 1993.

${ }^{10}$ BACHTLER, John e MENDEZ, Carlos. Who Governs EU Cohesion Policy? Deconstructing the Reforms of the Structural Funds. JCMS 2007, v 45, n. 3 (2007) p. 535-564.
} 
uma relação de confiança e de cooperação. Rozsa ${ }^{11}$ acrescenta que “[...] os portugueses são grandes diplomatas, eles são realmente fantásticos em falar, negociar, expressar suas vontades e convencer."

Outro ponto de semelhança no discurso dos atores foi o caráter técnico das negociações e a perspectiva da competência partilhada, da gestão partilhada ${ }^{12}$. A política regional não é de competência exclusiva da Comissão, é algo compartilhado com os Estados membros. Esta faz as propostas dos Regulamentos, e então são seguidos procedimentos regulares de joint decision entre os EM (Estados-membros), PE (Parlamento Europeu) e Comissão para fixar as novas regras. Isto é, basicamente, baseado num acordo entre todas estas instituições e governos. Na fase de negociação, “[...] a Comissão tem um papel na definição das estratégias e das principais linhas onde o investimento deveria ir" ${ }^{13}$. Os objetivos locais, contudo, muitas vezes mostram-se divergentes dos comunitários no processo negocial, é quando se manifesta na prática a força restritiva do framework europeu. A Comissão muitas vezes tem objetivos de equidade. Por estar fora do debate politico interno, a Comissão insiste para que os melhores projetos, que estejam mais maduros, com mais impactos, sejam os projetos escolhidos ${ }^{14}$.

Sobre a definição das prioridades estratégicas, o processo negocial envolve diálogo amplo, criação de consensos e aprendizado conjunto. Desde o QREN (Quadro de Referência Estratégico Nacional) e na definição do Quadro mais recente (2014-20, Portugal 2020), por exemplo, o investimento em infraestrutura tornou-se uma prioridade negativa no país, em função dos grandes investimentos que foram feitos anteriormente ${ }^{15}$, assim como o são os investimentos no parque escolar, no caso da região Centro, tendo em vista a magnitude dos investimentos realizados no QREN nesta área ${ }^{16}$. Como prioridade negativa, só podem ser realizados se justificados de uma maneira muito específica e fundamental. Segundo Rozsa ${ }^{17}$, a Comissão tem discutido com o governo português sobre esse assunto, procurando definir qual é o nível de investimento em infraestrutura que é realmente necessário. Definitivamente, a ênfase está mudando para áreas soft como competitividade, empresas e inovação.

A funcionária da Comissão confirmou, expressamente, a dificuldade de o público poder acompanhar as negociações - pois estas são fechadas. O processo de negociação não é público, o

\footnotetext{
${ }^{11}$ ROZSA, Judit Torokne. Representante da Comissão Europeia, DG-Regio, responsável por Portugal. Entrevista concedida à autora, 2014.

${ }^{12}$ Rozsa, ibid. PESSOA, Luiz Sá. Chefe da Representação da Comissão Europeia em Portugal. Entrevista concedida à autora, 2014. BOTELHO, Maria João e BRITO, Rita. Portugal: Ministério dos Negócios Estrangeiros (MNE) - DGAssuntos Europeus. Entrevista concedida à autora, 2014.

${ }^{13}$ ROZSA, ibid.

${ }^{14}$ PESSOA, ibid.

15 ROZSA, ibid. BOTELHO e BRITO, ibid. RODRIGUES, Alexandra. Diretora de Desenvolvimento Regional, Comissão de Coordenação e Desenvolvimento Regional (CCDR)-Centro. Entrevista concedida à autora, 2014.

${ }^{16}$ RODRIGUES, ibid.

${ }^{17}$ Ibid.
} 
que evidencia a falta de transparência dos processos políticos europeus e reforça o argumento do défice democrático. Rozsa ${ }^{18}$ revelou que, em alguns anos, vai haver um documento em que os funcionários farão um relatório sobre as negociações, mas vai ser muito geral, sem a possibilidade de seguir os detalhes dos acordos. De qualquer forma, ela confirmou, assim como o MNE, o que eles chamam de diálogo informal. Foram feitas seis ou sete rodadas de negociações com o governo sobre o Acordo de Parceria (Quadro Estratégico para 2014-20). "Nos preparamos para cada uma destas etapas [a divisão de Portugal da DG-Regio], construímos nossa posição, às vezes a gente deu algum retorno para os portugueses, mas são documentos muito internos, estes não são para o público", afirmou a funcionária entrevistada. Botelho e Brito ${ }^{19}$ também destacaram o diálogo informal e o descreveram como um diálogo vivo, frequente, que constitui-se em um processo hermenêutico, de interpretação das normas. "Há mais de um ano, tem havido reuniões sistemáticas com nossa unidade da DG-Regio da Comissão, onde foram mostrados os documentos todos, os diagnósticos prospectivos foram apresentados, foram debatidos." Posteriormente, na etapa formal de negociações, o governo português apresentou oficialmente o acordo, e a Comissão preparou as observações oficiais, que já haviam sido anteriormente acordadas e também não são públicas.

Ao longo de todo o processo negocial, destacou-se a construção do consenso estratégico, o aprendizado conjunto, o jogo diplomático do soft power. Hoje, os funcionários portugueses dominam a fase de programação estrutural e estão muito bem preparados. As divergências ocorrem não por falta de conhecimento e sim em função das definições estratégicas. Há posições e ideias divergentes e um esforço de convencimento recíproco. Em algumas áreas, a Comissão fez progressos, em outras, esgotados os argumentos, resta apenas a decisão política formal. Mas, em um balanço final, Rozsa ${ }^{20}$ mostrou-se otimista: “[...] nós vamos conseguir um bom resultado no final”.

Uma vez acordados os programas e definidas as estratégias, é o EM quem assume. Este tem que realizar a seleção, aprovação e monitoramento dos projetos. Assim, “[...] em nível de projeto, basicamente tudo é feito pelo Estado-Membro." ${ }^{21}$ A Comissão tem um papel muito limitado na definição concreta dos investimentos e instrumentos muito restritos para limitar, parar ou intervir.

As representantes do MNE relativizam mais a força do Estado português no processo, enfatizando a força restritiva das normas europeias. O fato de haver uma decisão formal da Comissão aprovando a base para se justificar a despesa (Quadros Estratégicos), dá à Comissão alguma margem de influência. Depois, a atuação estatal fica limitada por procedimentos à posteriori de acompanhamento, de fiscalização (pelo Tribunal de Contas da UE) e de auditoria, que

\footnotetext{
${ }^{18}$ Ibid.

${ }^{19}$ Ibid.

${ }^{20}$ Ibid.

${ }^{21}$ ROZSA, ibid.
} 
impõem uma disciplina normativa, o que garante que o sistema funcione coerentemente, de acordo com as regras ${ }^{22}$.

A seleção dos projetos é feita pelo Governo central. Este escolhe alguns projetos-chave prioritários; e há também a seleção de projetos via concursos (de livre concorrência) em que as pessoas físicas ou jurídicas podem se candidatar. A escolha é feita com base em critérios, pela equipe de assessoramento liderada pelo gestor (da referida unidade de gestão). Na fase inicial, os concursos estavam abertos em permanência, enquanto houvesse disponibilidade financeira. Mas isto não contribuiu muito para a seleção dos melhores projetos, pois a tendência foi financiar os primeiros projetos que iam se apresentando, e um bom projeto que fosse apresentando na fase final do período de programação poderia não ser financiado, caso já não houvesse mais disponibilidade financeira. Optou-se então por concursos não abertos em permanência. Agora há uma fase específica de seleção dos projetos - de acordo com as áreas e medidas identificadas nos programas para serem financiadas ${ }^{23}$.

Sobre alocação, os envelopes são definidos, em nível comunitário, pelo grau de desenvolvimento da região. Ou seja, os recursos da coesão destinados a Portugal dividem-se entre regiões dos objetivos um e dois e regiões em transição ${ }^{24}$ (exceto o Fundo de Coesão que é de gestão puramente nacional). Com base nessas restrições, o Governo central é quem decide como dividir o dinheiro entre diferentes programas ${ }^{25}$.

Ainda assim, como destacado anteriormente, e também no caso português, o Estado tem certa flexibilidade para realizar mudanças na alocação. Quando se faz a repartição comunitária do dinheiro pelos Estados, ela se faz por regiões, e o país então recebe a soma destes recursos regionais. No caso das Regiões Autônomas (RAs), em que há governos democraticamente eleitos e com competências próprias, os recursos finais a estas destinados via Governo central não diferem muito dos envelopes definidos inicialmente. O Fundo de Coesão tem gestão centralizada e é utilizado pelo Estado com certa flexibilidade, no sentido de equilibrar as eventuais necessidades regionais (inclusive das RAs). No caso dos Fundos Estruturais, há certa flexibilidade dentro da tipologia de regiões e entre estas. Portanto, entre as regiões menos desenvolvidas (abarcadas pelo objetivo 1: Norte, Centro, Alentejo e Açores) há certa margem de manobra para reorganização

\footnotetext{
${ }^{22}$ BOTELHO e BRITO, ibid.

${ }^{23}$ Idem, ibid.

${ }^{24}$ São elegíveis para o objetivo 1 (Convergência) as regiões onde o PIB per capita é 75 por cento menor do que a média europeia. Todas as outras regiões (sem zona geográfica específica) são elegíveis para o objetivo 2 (Competitividade regional e emprego). O efeito estatístico da mudança da UE-15 para a UE-25, com a diminuição da média do PIB per capita, contribuiu para a definição de áreas de transição que continuariam recebendo recursos dos Fundos: phasing-out (abaixo da UE-15, mas não da UE-25) e phasing-in (regiões recentemente saídas da convergência, ou seja, que ultrapassaram o objetivo 1 recentemente).

${ }^{25}$ Idem, ibid. e ROZSA,ibid.
} 
destes montantes, assim como ocorre dentro das regiões mais desenvolvidas (objetivo 2: Lisboa e a Madeira). No QREN, a região de transição que ficava à parte era o Algarve. Ainda assim, havia alguma possibilidade, numa porcentagem mínima de 2 por cento, de se poder transferir parte dos recursos do envelope de uma região para outra, o que no caso do Algarve é muito importante. Nesta região portuguesa de veraneio, a população residente é relativamente pequena, mas a quantidade de turistas em determinadas épocas do ano, em especial no verão, é enorme e, portanto, as infraestruturas necessárias (como saneamento básico e hospitais, por exemplo) têm que ser redimensionadas a esta base, e não com base na população residente, como é o cálculo inicial comunitário $^{26}$.

A participação da Comissão na implementação restringe-se aos Comitês de Monitoramento, em que a instituição participa como observadora, sem poder de voto, apenas em caráter recomendatório. Há encontros anuais com as CCDRs (Comissão de Coordenação e Desenvolvimento Regional) e com outros stakeholders regionais, num processo contínuo de monitoramento, cujo foco é verificar a forma como os programas são implementados, como estão sendo gastos os recursos e se os objetivos estão sendo alcançados. Pode-se interpretar as auditorias como parte deste processo. Neste sentido, as instituições nacionais encarregadas da gestão do programa têm que assegurar o cumprimento das regras e a gestão financeira e há também auditoria externa (da Comissão). A avaliação fecha este processo e é realizada conjuntamente, parte pelas regiões, parte pelo Observatório (instituição nacional de gestão) e também por consultores externos.

Sobre a questão da corrupção, a representante da Comissão afirmou que a situação não é ruim, e que os casos são muito raros. Há alguns casos de irregularidades, caso de as regras não terem sido corretamente seguidas, o que é passível de correção e diferente de corrupção. Segundo Rozsa $^{27}$, o sistema de gestão e controle financeiro em Portugal está entre os melhores da Europa e funciona muito bem ${ }^{28}$.

Com base na relação entre os níveis nacional e comunitário, podemos então compreender a implementação da PCEST como um processo de competências parcialmente partilhadas entre estes, no âmbito do que podemos definir como um processo de governação multinível assimétrica. A força da Comissão é ampla em principalmente uma fase, no tocante ao desenho institucional. As restrições comunitárias são definidas no processo negocial e atuam de forma negativa, na coibição de programas desencaixados dos objetivos e estabelecimento de prioridades negativas. O processo

\footnotetext{
${ }^{26}$ BOTELHO e BRITO, ibid.

27 Ibid.

${ }^{28}$ Visão divergente, no entanto, é apresentada por Santos: “[...] os fundos estruturais e de coesão foram desbaratados no que constitui a história mais secreta da corrupção em Portugal”. SANTOS, Boaventura de Sousa. Portugal - Ensaio contra a auto-flagelação. $2^{\mathrm{a}}$ ed. Coimbra: Ed. Almedina, 2012, p. 164.
} 
negociado e pouco transparente, acarreta um reforço mútuo destes polos centrais do poder europeu (UE e Governo central). A Comissão não participa diretamente na implementação, apenas como observadora $^{29}$ e realiza avaliações de forma compartilhada com os Estados e autoridades subnacionais. Há um diálogo ampliado entre Portugal e a Comissão, com relações fluidas e cordiais, mas tendo em vista a ampla rationale e definição dos programas em nível comunitário; quando se passa à implementação, o EM tem grande margem de manobra para definir os projetos (meios) e a alocação de recursos. Em suma, a Comissão tem uma atuação restrita mas influente, enquanto o Estado tem uma ampla atuação em todas as fases.

Após a análise dos níveis supranacional e nacional, continuaremos com a abordagem deste último nível, acrescentando à reflexão os aspectos subnacionais.

\section{O processo de implementação nas regiões portuguesas: a GMN assimétrica}

O foco da presente análise recai sobre a participação de destacados atores portugueses no processo de implementação: o governo central e suas estruturas desconcentradas de gestão; a participação subnacional via CCDRs (Comissões de Coordenação e Desenvolvimento Regional); as Regiões Autônomas (RAs) e a sociedade civil.

Apesar de ser um Estado unitário, Portugal tem duas regiões autônomas (RAs), Açores (RAA) e Madeira (RAM) que foram criadas em 1976, pela via constitucional, consagrando uma vontade popular autonômica de longa data. Esta esteve historicamente fundamentada na insularidade, na distância geográfica e política do poder central e sua condição periférica ${ }^{30}$. Estas regiões passaram a ter um regime administrativo próprio, em que as assembleias e governos regionais têm amplos poderes para definir as suas políticas, exceto no que diz respeito à política externa, segurança e defesa, que são de competência do Governo Central ${ }^{31}$.

O processo de regionalização, a formação de autarquias de âmbito regional, foi prevista na Constituição pós-Revolucionária. No entanto, muitas razões contribuíram para as falhas das tentativas de descentralização: a ênfase do debate na questão dos limites espaciais e não na divisão de competências, o que inviabilizou o processo; pressões corporativas do centro (percepção de perda de poder e empregos); desconfiança das decisões técnicas tomadas em nível intermediário (desconfiança sistemática da eficácia da partilha de poder); dificuldade de implementar reformas

\footnotetext{
${ }^{29}$ ROZSA, ibid.

${ }^{30}$ FERNANDES, Antonio Teixeira. Descentralização e Teoria do Estado. Colóquio sobre - La Déscentralisation: Évaluation d'um Thème de Recherches. Universidade de Orléans, 1 e 2 de Out., 1987. Disponível em: [http://repositorio-aberto.up.pt/bitstream/10216/8949/2/1690.pdf].

${ }^{31}$ Ref. [http://www.portugal.gov.pt/pt/a-democracia-portuguesa.aspx]. Acesso em: 09 Set. 2014.
} 
mais profundas em governos fracos e transitórios; preferência centralista em governos fortes e duradouros; peso da tradição administrativa centralizadora e não suficiente reclamação de poder pelas periferias ${ }^{32}$. As eleições locais parecem ter suprido o anseio democratizante. Assim, no Referendo realizado na década de 1980, de caráter não vinculativo, a regionalização perdeu. Segundo Oliveira ${ }^{33}$, tal processo foi conduzido pelo Governo com inabilidade e pouca coerência entre o objetivo e a proposta formulada. Um dos problemas destacados na condução do Referendo é que este misturava a questão da descentralização com a da definição das fronteiras regionais. Assim, “[...] ao forçar a adoção de uma dada divisão espacial regional com a qual o governo se identificava (oito regiões) misturou no 'não' votos com sentido distinto." ${ }^{34}$ Em geral, destacou-se também uma forte mobilização dos centralizadores de todos os partidos.

O sistema semipresidencial parlamentarista português ${ }^{35}$ está concentrado em torno de dois partidos, o PS (Partido Socialista) e o PSD (Partido Social Democrata). Alguns indicadores mostram que há uma percepção na opinião pública portuguesa de proximidade ideológica dos principais partidos de governo (o que acontece também com os partidos centristas em outros países europeus). A literatura sobre o tema destaca os seguintes elementos de convergência advindos da dinâmica interna: a esquerdização política inicial (pós-Revolução); a busca de redução da influência comunista na transição; a exclusão do PCP (Partido Comunista Português) do espectro governativo, que teria empurrado o PS para a direita em termos de coligações e políticas adotadas; assim como as estratégias eleitorais catch-all dos dois partidos adotadas desde meados da década de $1980{ }^{36}$. Esta perspectiva foi fortalecida em nível internacional pelas teses sobre o fim da divisão ideológica esquerda-direita (com destaque para os escritos de Anthony Giddens) que foram depois amplamente contestadas por evidências de manutenção das ideologias partidárias e sua influência nos programas adotados. De acordo com esta linha, Guedes ${ }^{37}$ analisa as principais diferenças programáticas entre o PS e o PSD em Portugal, entre 1991-2009, que confirmam a diferença de foco entre a direita e a esquerda. Os temas sociais e a ideia de Estado regulador são mais relevantes nos programas do PS;

\footnotetext{
${ }^{32}$ OLIVEIRA, Luís Valente de. A Regionalização em Portugal. In: COSTA, J. S. e NIJKAMP, P. (coord.). Compêndio de economia regional: volume 1: teoria, temáticas e políticas. Cascais: Principia, 2013.

${ }^{33}$ Ibid.

${ }^{34}$ Idem, ibid.

${ }^{35}$ Para uma discussão sobre as especificidades do sistema português, em especial sobre a força do Primeiro-Ministro, ver Dissertação defendida na UTL: LINDO, Carlos Manuel G. L. (2014). "O Semipresidencialismo no Portugal Democrático - Um estudo longitudinal". O autor analisa o que chamou de transição do semipresidencialismo para o "presidencialismo do Primeiro-Ministro". Disponível em: [https://www.repository.utl.pt/handle/10400.5/6563]. Acesso em: 03 Out. 2014.

${ }^{36}$ GUEDES, Nuno. Convergência ideológica? Uma análise comparada dos programas eleitorais do PS e do PSD (19912009). Sociologia, Problemas e Práticas, Lisboa, nº 68 (2012) p. 103-125.

${ }^{37}$ Ibid.
} 
enquanto os temas da lei e da ordem, assim como a ortodoxia econômica são temas mais frequentes nos programas do PSD.

Apesar destas diferenças fundamentais, destaca-se a convergência em relação à centralidade da opção europeia como via principal de inserção internacional. Para o alcance dos principais objetivos, a integração europeia foi um dos meios prioritários para ambos os partidos, o que embasou a colaboração entre estes nas décadas de 1980 e $1990^{38}$. O caminho europeu acabou por constituir, assim, um projeto de Estado.

Em relação à implementação da política de coesão em Portugal, destacaram-se também mais continuidades do que mudanças entre governos, estas largamente retóricas. Em sendo uma "área relativamente consensual", o principal vetor de mudança foi mesmo a dinâmica do desenvolvimento 39

Em função dos imperativos da política de coesão europeia, destacou-se, em Portugal, dinâmica de grande capacitação institucional e em termos de construção de planejamentos estratégicos. As condicionantes de tal política foram a existência de estruturas nacionais dedicadas à gestão, acompanhamento e avaliação dos Fundos. Foram então criadas entidades novas e estruturas próprias de gestão - Instituto Financeiro para o Desenvolvimento Regional (IFDR), no que respeita ao FEDER e ao Fundo de Coesão, e o Instituto de Gestão do Fundo Social Europeu (IGFSE). Estas instituições estiveram ao lado da administração pública tradicional e assim puderam oferecer maior especialização, remuneração e refrescamento ao aparelho tradicional do Estado ${ }^{40}$. A estrutura interna do QREN tinha um gestor responsável com uma equipe para cada programa, a do próximo período (2014-20) será gerida pela recém criada ADC (Agência para o Desenvolvimento e Coesão) 41 .

O Observatório foi uma destas novas estruturas de gestão criadas para auxiliar o governo central na implementação dos Fundos Estruturais. Nos anos 1980, uma pessoa era responsável pela interlocução com a Comissão. No período 2000-6, esta função foi acolhida pelo Observatório do QCA III - que tinha uma pequena estrutura de menos de 10 pessoas e dedicava-se ao acompanhamento, monitoramento e avaliação dos Fundos. No Observatório do QREN, esta estrutura foi reforçada, chegando a 30 pessoas. Esta manteve suas competências essenciais e ganhou outras diversas como prestar informação ao público e realizar a coordenação técnica da gestão dos Fundos. Recentemente, no quadro de programação que está sendo elaborado para o período 2014-

\footnotetext{
${ }^{38}$ Idem, ibid. e PRIDHAM, Geoffrey. A integração europeia e a consolidação democrática da Europa do sul. In: PINTO, António Costa e TEIXEIRA, Nuno Severiano (org.) A Europa do Sul e a construção da União Europeia (19452000). Lisboa: Universidade de Lisboa, Instituto de Ciências Sociais, 2005.

${ }^{39}$ BOTELHO e BRITO, ibid.

${ }^{40}$ FEIO, Paulo Areosa. Coordenador do Observatório do QREN. Entrevista concedida à autora, 2014.

${ }^{41}$ BOTELHO e BRITO, ibid.
} 
20 (Portugal 2020) tais funções foram claramente integradas na administração pública central - por meio da constituição da Agência para o Desenvolvimento e Coesão ${ }^{42}$. Esta ganhou competências adicionais de coordenação e resultou da fusão das três referidas Instituições (Observatório do QREN, IFDR e IGFSE) no contexto da crise e da importância acrescida dos Fundos para a economia nacional. A Direção tomou posse em dezembro de 2013 no sentido de racionalizar a eficácia dos gastos estruturais e diminuir os custos. O Ministro do Desenvolvimento Regional, Poiares Maduro, destacou o aumento da capacidade administrativa, a melhora na eficiência da integração entre os Fundos, e a elevação da cúpula da administração dos Fundos ao patamar primeiro da administração pública. Os fundos europeus passaram a ser considerados como alavanca essencial para o crescimento econômico e social do país, no contexto de restrição de gastos. Segundo o Ministro, as empresas serão as grandes beneficiárias do próximo quadro.

Em perspectiva histórica, notou-se grande avanço em termos de aprendizagem e participação de Autoridades locais e stakeholders setoriais no processo, fortalecendo o diálogo democrático. No QREN, apesar da referência da Comissão à dificuldade de avaliar o Princípio da Parceria, o Governo Português esforçou-se em fazer uma síntese das principais Reuniões, Seminário e Conferências de apresentação e debate. Contudo, como afirmou a Comissão, é difícil avaliar em que medida o resultado desses debates têm sido considerado pelo Governo Central.

“O QREN menciona que vários contributos (inputs) dos stakeholders acima mencionados foram tidos em conta no QREN submetido. No entanto, nenhuma evidência para apoiar esta afirmação foi apresentada. Portanto, não podemos avaliar o valor acrescentado prático e o nível de envolvimento dos parceiros sociais e da sociedade civil no processo de formulação política." 43

Ainda assim, no cotidiano português recente, notou-se grande pressão social sobre a gestão dos Fundos, em especial via disputas públicas por recursos (por exemplo, entre Lisboa e Porto) e debates com grande visibilidade e reflexos na imprensa portuguesa. Também em relação à avaliação, esta foi destacadamente realizada com a contribuição regional. Segundo Rodrigues ${ }^{44}$, cada programa operacional tinha uma pequena estrutura de acompanhamento e avaliação, um miniobservatório, que colaborava com o Observatório do QREN, que se alimentava das bases de dados deste, assim como de cada programa operacional.

No processo de implementação da PCEST nas regiões continentais, em especial na gestão dos Programas Operacionais Regionais (PORs), as Instituições de maior destaque foram as CCDRs

\footnotetext{
42 FEIO, ibid. Ver documentação relativa à criação da Agência no sítio do Observatório do QREN [http://www.observatorio.pt/].

${ }^{43}$ QREN - Quadro de Referência Estratégico Nacional, 2007-2013. Lisboa: Ed. Observatório do QCA III, 2007, p. 128. Disponível em: [www.qren.pt]. Acesso em: Fev, 2013.

${ }^{44}$ Ibid.
} 
(Comissões de Coordenação e Desenvolvimento Regional). Estas são parte da administração central e têm a função de coordenar e articular as várias políticas regionais. Estas instituições existem desde antes do 25 de abril e estavam voltadas à realização dos Planos de Fomento. São então estruturas tradicionais de planejamento, tem história de competência técnica muito relevante e, com a Revolução, deram apoio à instalação das autarquias locais. As então CCRs (Comissões de Coordenação Regional) contribuíram para capacitar esta nova instância do poder político e tiveram enorme relevância na fundação da nova administração pública portuguesa ${ }^{45}$. Desde fins dos anos 70, sua área territorial de atuação era semelhante à de hoje.

Além do apoio às administrações locais, as funções das CCDRs relacionam-se também com as políticas nacionais ambientais; desenvolvimento e implementação das políticas de desenvolvimento regional definidas em nível nacional; fiscalização; e ordenamento do território, com a coordenação territorial de programas de natureza diversa ${ }^{46}$. Com a integração europeia, a instituição passou a ser gestora dos Programas Operacionais Regionais (PORs), em que a região pode definir suas opções estratégicas (em relação aos seus aportes financeiros) sob a orientação nacional.

A política portuguesa de desenvolvimento regional concentrou-se, em termos de recursos, nos projetos relativos à política de coesão. Essa significativa dotação financeira comunitária agregou uma capacidade de mobilizar atores para áreas considerada fundamentais. A gestão dos Programas Regionais, inclusive em termos de alocação, acabou por conferir às CCDRs certo capital político ${ }^{47}$, e as Autoridades subnacionais tiveram uma força destacada nos PORs ${ }^{48}$. Na fase inicial de instalação dos Fundos (QCAs I e II), os PORs (somados os programas das cinco regiões continentais e das duas RAs) respondiam por cerca de 20 por cento dos aportes dos Fundos ${ }^{49}$.

Há um grande reconhecimento na literatura de que o princípio da parceria teve melhores chances de realização nas fases de implementação e avaliação. A maior autonomia regional na construção dos PORs e na concepção de projetos locais teve relação com as necessidades de maior legitimidade e de informação e recursos locais por parte dos Governos centrais ${ }^{50}$. Ademais, as

\footnotetext{
${ }^{45}$ FEIO, ibid. NEVES, Mario. Diretor de Desenvolvimento Regional, CCDR-Norte. Entrevista concedida à autora, 2014. MOZZICAFREDDO, Juan. La decentralisation administrative et les innovations en matiére de politiques regionales au Portugal. Sociologia, Problemas E Práticas, Lisboa, n. 41, (2003), p. 151-179.

${ }^{46}$ RODRIGUES, ibid. Ver sites das CCDRs, em que há muita informação disponível sobre suas atuações recentes.

${ }^{47}$ FEIO, ibid.

${ }^{48}$ PESSOA, ibid.

${ }^{49}$ MEDEIROS, Eduardo. A Política de Coesão da União Europeia em Portugal (1989-2013): contribuições para o desenvolvimento territorial. In: Centro de Estudos Geográficos da Universidade de Lisboa (CEG), Instituto de Geografia e Ordenamento do Território (IGOT), Lisboa, 21/08/2013. Disponível em: [http://ww3.fl.ul.pt/pessoais/Eduardo_Medeiros/docs/PC_EM_21_08_2013.pdf]. Acesso em: Jan 2014.

${ }^{50}$ As opções europeias neste sentido foram diversas, variando da autêntica descentralização à "[...] desconcentração do processo decisório sob controle estatal”. O papel dos governos subnacionais em criar PORs foi maior na Bélgica,
} 
relações entre os governos centrais e subnacionais em diversos países europeus estiveram envolvidas em conflitos político-partidários ${ }^{51}$, o que também ocorreu no caso de Portugal, onde os governos subnacionais pressionaram pela distribuição dos Fundos de acordo com a lógica nacional já definida de distribuição, a fefização, provavelmente no sentido de procurar evitar mudanças de alocação ao sabor da lógica nacional-partidária.

A dinâmica chamada de fefização refere-se ao Fundo de Equilíbrio Financeiro (FEF), que especifica a parcela que cabe aos municípios dos recursos nacionais. Esta repartição é baseada em um conjunto de critérios que levam em conta, por exemplo, população e relevo. Esta mesma lógica nacional de distribuição foi, durante muito tempo, levada para os fundos comunitários. E o impacto desses recursos avultados nas autarquias foi tremendo, porque o montante de receitas nacionais para as transferências para os municípios é muito inferior aos fundos comunitários ${ }^{52}$. Entende-se assim o foco das autarquias em gastar os recursos disponíveis, mesmo que em obras não tão relevantes em termos produtivos, no sentido de evitar a possível perda desses recursos em momento posterior.

A batalha entre os vetores de centralização e descentralização ocorreu de maneira contínua $^{53}$. De qualquer forma, a preparação do QCA III talvez tenha representado o esforço mais relevante de pensar estrategicamente o desenvolvimento das regiões, obviamente em articulação com a estratégia nacional. Tal fato se refletiu no aumento relativo do orçamento gerido regionalmente pelas CCDRs. O somatório dos PORs passou a responder por cerca de 40 por cento dos Fundos ${ }^{54}$, e as CCDRS passaram então a ter atuação mais destacada no sentido de buscar maior eficiência na utilização dos recursos. O esforço realizado entre 1998 e 2000 de definir uma estratégia nacional com forte componente regional correspondeu ao esforço de melhor articulação destas duas escalas. Foi um processo muito participado, com coordenação do Departamento de Perspectiva e Planeamento (DPP), das CCDRs e uma participação significativa da Academia, por meio de Universidades e Consultorias ${ }^{55}$.

A preparação do QREN (em 2005-6) procurou reproduzir, em grande medida, este exercício de diálogo democrático. Tal dinâmica manteve-se, porventura de forma menos intensa, no plano regional, tendo em vista a base mais robusta das políticas de âmbito nacional (com exceção das RAs). A coordenação dos Fundos mudou de uma lógica ministerial, onde se localizavam boa parte

\footnotetext{
Alemanha e Espanha, embora as relações entre os governos regionais com os governos central e locais variem entre esses países. Nos outros países, atores subnacionais desempenharam um papel menor, como na França, Grécia, Irlanda e Reino Unido. (MARKS, ibid, 1996, p. 404).

${ }^{51}$ MARKS, ibid., 1996.

52 NEVES, ibid.

${ }^{53}$ Idem, ibid. e RODRIGUES, ibid.

${ }^{54}$ MNE Ministério dos Negócios Estrangeiros. Informação Estatítica - União Europeia, Estados-membros. DGAE, MNE, dez. 2013.

${ }^{55}$ FEIO, ibid.
} 
das barganhas municipais e passou a ser temática. Tal coordenação passou a ser definida no nível nacional, acarretando uma diminuição da importância relativa do nível regional ${ }^{56}$. Paralelamente, o somatório dos PORs mostrou queda relativa e passou a responder por cerca de 34 por cento dos Fundos ${ }^{57}$. Rodrigues ${ }^{58}$ reforça este argumento. No QREN, o POR-Centro foi feito com base em “[...] um levantamento da documentação que existia e uma definição em gabinete”; a gestão do FSE aconteceu em nível nacional; assim como a maior parte do desenho das outras políticas que, em geral, seguiram uma lógica mais centralista, com exceção dos PORs.

Em termos de elegibilidade, na fase inicial da política de coesão, todas as regiões portuguesas faziam parte do objetivo 1 (convergência). No período 2007-13, a maior parte de Portugal ainda era do objetivo 1 (Norte, Centro, Alentejo e Açores), havia uma área de transição (Algarve) e as regiões com maior PIB per capita relativo, Lisboa e Madeira, conformavam as áreas cobertas pelo objetivo 2 .

Destacadamente, a região de Lisboa diminuiu ao longo do tempo. Parte do Vale do Tejo (VT) foi incorporada no Centro e outra no Alentejo. De acordo com o governo português, a lógica era passar esses territórios para as regiões do objetivo 1 - para que pudessem manter uma maior capacidade de recepção de financiamento europeu. A Comissão não teve influência sobre esse processo, tendo em vista que a definição das regiões é de competência estatal. Ao longo dos diversos períodos de programação, a região de Lisboa recebeu grandes aportes financeiros. Por exemplo, alguns dos projetos destacados na região foram: o reforço no abastecimento de água realizado pela empresa responsável por este serviço em Lisboa (EPAL), que passou a abastecer trinta municípios da margem norte do Tejo; a despoluição do Tejo e a construção de estações de tratamento de águas residuais. Nesse sentido, as justificativas para o volumoso aporte de recursos em Lisboa referem-se à concentração, na cidade, da maior parte da população do país; do alegado efeito de spillover, resultante dos impactos positivos que seriam sentidos em outras regiões do país por meio dos grandes investimentos estruturais em Lisboa, e assim da eficiência em concentrar determinados investimentos na capital; e de sua importância no desenvolvimento de determinadas estruturas administrativas e de ensino, como laboratórios e Universidades ${ }^{59}$.

Com a região passando a estar classificada no objetivo dois, a margem para a escolha do tipo de intervenção passou a ser muito mais restrita do que nas outras regiões, as prioridades de investimento passaram a ser menores e devem estar relacionadas com as deficiências identificadas. Por exemplo, há ainda na região um elevado grau de abandono escolar (que já foi reduzido de cerca

\footnotetext{
${ }^{56}$ Idem, ibid.

${ }^{57}$ MNE, ibid.

${ }^{58}$ Ibid.

${ }^{59}$ PESSOA, ibid.
} 
de 40 por cento para algo em torno de 20 por cento, mas este grau ainda é maior do que a média europeia de 12 por cento). Assim, houve um reforço de verbas para Lisboa, mas a contrapartida é que as intervenções sejam realizadas em ações que respondam a este problema ${ }^{60}$.

Uma novidade relevante destacada a partir do QREN foi o incentivo ao nível intermunicipal. O caso do Centro oferece um bom exemplo dessa dinâmica. Foram apoiados, por convite, projetos integrados liderados pelas três Universidades da região (localizadas em Coimbra, Aveiro e Covilhã) e o apoio aos projetos foi condicionado a serem integrados numa estratégia de médio prazo. Essa ampla cobertura regional possibilitou a dotação da região em termos de infraestruturas científicas e tecnológicas articuladas ${ }^{61}$. Em termos gerais, desde o QREN, as autarquias e municípios podem dispor de financiamentos no contexto das comunidades intermunicipais - associações entre municípios em nível das NUTS 3. Para determinadas temáticas, essas associações podem apresentar projetos que terão financiamento e serão geridos por essa comunidade intermunicipal. "Portanto, os atores locais são muito chamados a ter, nessa dinâmica da governação multinível, um grande protagonismo." 62 Esta dinâmica continuará no período 2014-20, em que as comunidades intermunicipais serão essencialmente financiadas por meio das chamadas Intervenções Territoriais Integradas (ITIs).

Um das maiores tensões no debate sobre o desenvolvimento de Portugal refere-se à questão das destacadas diferenças entre o litoral e o interior, em especial nas regiões Centro e Norte do país, em que o interior concentra as zonas de baixa densidade populacional. Cerca de 2/3 da região centro constitui-se de área rural. Estas tiveram dificuldades destacadas em se afirmar, e "[...] houve políticas de apoio à baixa densidade que nunca surtiram muitos efeitos." (RODRIGUES, 2014). Desde o final do QREN, portanto, houve avisos de concursos só para territórios de baixa densidade. A dimensão dos apoios era pequena, e o objetivo, por exemplo, era a criação de um posto de trabalho via incentivos às microempresas - no intuito de dinamizar os territórios mais desfavorecidos. Estas experiências, ainda que de pequena dimensão, tiveram resultados positivos. Para o período 2014-20, então, de forma análoga ao que se faz em nível comunitário, a CCDRCentro classificou os seus microterritórios em três categorias: coesão, competitividade e transição, com o objetivo de desenvolver um mecanismo de majoração dos territórios incluídos na categoria de coesão. Ainda assim, no caso do sistema de inovação, por exemplo, boa parte dos investimentos concentrou-se no litoral, onde está a maior parte das grandes entidades, Universidades e Centros de

\footnotetext{
${ }^{60}$ BOTELHO e BRITO, ibid.

${ }^{61}$ RODRIGUES, ibid.

${ }^{62}$ BOTELHO e BRITO, ibid.
} 
Investigação ${ }^{63}$.

\section{Avanços e dificuldades destacadas do processo de implementação}

No processo de transposição dos ideais estratégicos para a prática política, destacaram-se alguns problemas de implementação. No passado, muitos projetos foram realizados pois, no processo de alocação, de forma semelhante à dinâmica da política interna, a lógica era a competição intermunicipal por recursos e a divisão por todos, o que resultou em verbas avultadas para diversos municípios. Muitos projetos realizados então foram sobredimensionados e tiveram pouco impacto em termos de crescimento econômico sustentável ${ }^{64}$, o que ficou conhecido entre os atores relevantes como o problema das piscinas, usando-as em sentido ilustrativo, mas tais obras podiam referir-se também à construção de fontes, complexos esportivos (em locais com poucos atletas) etc. Rozsa ${ }^{65}$ completa relatando que à medida que um determinado município conseguia construir uma infraestrutura específica, em seguida a localidade mais próxima também a queria, para igualar-se ao vizinho e, neste sentido, poderia agradar o público local. Esta é uma dinâmica muito difícil de ser tratada em nível estratégico, em que as limitações definidas são iguais para todos. Entende-se assim a opção da Comissão em evitar restrições gerais e manter um quadro amplo de opções, no sentido de poder encaixar as diversas especificidades. Outro problema destacado foi a questão de manutenção de tais estruturas, pois a UE não financia este aspecto.

A baixa capacidade de definição estratégica nas municipalidades do continente e de estabelecimento de uma lógica desenvolvimentista regional também foi um elemento dificultador. Assim, muitas vezes, autoridades subnacionais procuravam realizar projetos que não se adequavam à lógica de criação de uma base sustentável para o desenvolvimento da região, concentrando-se na utilização dos recursos disponíveis. Pessoa ${ }^{66}$ mencionou que alguns Representantes municipais na região do Algarve, por exemplo, insistiram em realizar um programa de cooperação com os países africanos de língua portuguesa. Estes queriam recursos dos Fundos estruturais, em especial, porque poderiam ser comandados diretamente pelas Autoridades locais (os Autarcas). Mas, como estes tipos de programas não estão incluídos na abordagem comunitária, foram recusados. Nestes casos mais graves, a Comissão teve que dizer não ${ }^{67}$. O centro das ocupações desta instituição comunitária é verificar a legalidade, se os regulamentos nacionais estão de acordo com as amplas estratégias

\footnotetext{
${ }^{63}$ RODRIGUES, ibid.

${ }^{64}$ PESSOA, ibid.; NEVES, ibid.

65 Ibid.

${ }^{66}$ Ibid.

${ }^{67}$ ROZSA, ibid. PESSOA, ibid.
} 
comunitárias. Ainda assim, a margem de manobra do EM é muito ampla, assim foi possível justificar a construção das piscinas.

Percebe-se então a grande responsabilidade do Estado membro em definir o seu caminho estratégico, no contexto do framework europeu. Assim, o EM acaba mais responsabilizado por suas próprias opções estratégicas, assim como pelas opções das municipalidades continentais (quer por ação ou por omissão em relação a estas, o que acaba por ser confortável para a Comissão). Por outro lado, o problema das piscinas apresenta contrafactual à ideia de pouco poder local na política de coesão. Se as municipalidades queriam as piscinas e conseguiram, mesmo eventualmente sabendo que nem sempre este era o melhor investimento, então alguns representantes municipais tiveram força em termos de definição de projetos (pela via da fefização). Isso significa que o governo central controlou parte significativa do orçamento, mas também facilitou a pulverização de parte dos recursos - dentro da lógica da política interna.

Um dos grandes desafios então foi o de aumentar a racionalidade produtiva dos gastos municipais. Em Portugal, esta dificuldade foi ampliada pela falta de articulação em nível intermédio, o que se está tentando minorar com o reforço do nível intermunicipal. Entende-se assim a busca contínua da Comissão em tentar, gradativamente, ir amarrando mais a questão temáticoestratégica.

Outro problema destacado em Portugal foi a questão das PPPs (Parcerias Público-Privadas), que não se restringiram apenas aos financiamentos comunitários. Estas acabaram por gerar certos problemas para o governo português. Eram soluções para grandes projetos de infraestruturas, em que os encargos eram altos (por exemplo, a construção da ponte Vasco da Gama sobre o Rio Tejo). Com base numa engenharia financeira e empréstimos, cuja expectativa de receita era alta, podia-se atrair o investimento privado ou associá-lo ao investimento público. No caso da ponte lisboeta, a empresa participou no financiamento e tinha depois direito a arrecadar as receitas. A estimativa da receita privada não se concretizou (pois não estava muito ajustada à realidade e por sofrer, posteriormente, o impacto da crise). Como os contratos garantem ao privado um montante determinado de receitas, o Estado tem que ressarci-lo e, portanto, tem custos muito elevados. Estas faturas elevadas apareceram numa fase posterior. Percebeu-se então que, da forma como foram feitas, as PPPs não foram um bom negócio para o Estado - pois, se havia prejuízo, o Estado arcava e, no caso de lucro, o parceiro privado é quem ganhava. A ideia, em teoria, era boa, mas precisa haver uma adequada repartição dos custos e benefícios, assim como um cálculo real das receitas que serão geradas por essas infraestruturas ${ }^{68}$.

${ }^{68}$ BOTELHO e BRITO, ibid. 
Apesar desses problemas, ao longo dos diversos períodos de programação, percebeu-se grande evolução local em termos de capacitação, conhecimento, desenvolvimento de projetos e participação política, um processo constante de aprendizado e aprimoramento de práticas locais e regionais, assim como uma grande ampliação do diálogo, da aproximação com os principais stakeholders regionais e, assim, do reforço da GMN. Mais uma vez, os avanços recentes na experiência da região Centro são emblemáticos neste sentido ${ }^{69}$.

Na definição do Quadro estratégico para o período 2014-20 (Portugal 2020), a Comissão Europeia definiu um conjunto de objetivos para os quais todos os países e regiões devem contribuir. De acordo com estas orientações, o novo Acordo de Parceria com a Comissão Europeia definiu as prioridades nacionais e os objetivos esquemáticos para os quais todos vão contribuir. Nesta definição, agora há condicionalidades estratégicas comunitárias. Por exemplo, parte significativa dos aportes deve estar relacionado à competitividade (cerca de 50 por cento); uma outra parcela deve contribuir para a economia do baixo carbono, o que condiciona a "[...] uma ginástica na construção e redistribuição desses valores" 70 .

O Diretor de Desenvolvimento Regional do Norte criticou o aumento gradativo da contratualização por parte da Comissão, em especial a criação de condicionalidades gerais, sem a diferenciação por países. Por exemplo, a condicionalidade de 50 por cento dos investimentos em competitividade. A questão central é que, às vezes, há baixa capacidade de absorção dos recursos e não há a quantidade de recursos humanos necessários para a consecução destes investimentos. Neves ${ }^{71}$ afirmou, então, que as maiores dificuldades em relação aos Fundos em Portugal foram problemas de gestão (não de formulação).

No processo de formulação do novo Quadro (2014-20), houve, desde meados de 2013, encontros conjuntos entre o Governo central e os Representantes das regiões (CCDRs) em torno da construção de um acordo nacional articulado regionalmente, sujeito às decisões ministeriais dos determinados setores relevantes, para definir as políticas de abrangência nacional e regional. Por exemplo, políticas de qualificação dos recursos humanos são nacionais, depois desenvolvidas à escala regional. Já os projetos de caráter municipal ou intermunicipal são definidos regionalmente.

\footnotetext{
${ }^{69}$ Tal dinâmica ocorreu também, em maior ou menor proporção, nas outras regiões do país (Norte, Lisboa, Algarve e Açores), em que pudemos perceber, vivenciar ou ouvir relatos de dinâmicas semelhantes. Acreditamos que também tenha ocorrido no Alentejo, mas não conseguimos confirmar esta hipótese com a Diretoria de Desenvolvimento Regional da CCDR-Alentejo e também, no início de 2014, quando se estava fechando o novo Quadro, Portugal 2020, e os PORs, não houve eventos de destaque como os que ocorreram em outras regiões, ou pelo menos não foram abertos ao público. Mas como parte das orientações para as CCDRs são nacionais, acreditamos que deve ter havido alguma dinâmica neste sentido. Sobre a Madeira, ver mais um exemplo recente de concentração de poderes: [http://www.publico.pt/politica/noticia/jardim-concentra-poder-decisorio-e-elimina-caractervinculativo-dos-pareceres1672766]. Acesso em: 13 Out. 2014.

${ }^{70}$ RODRIGUES, ibid.

${ }^{71}$ Ibid.
} 
Nessa preparação, foi identificado um plano de ação regional com base em muitas interações com os staholders setoriais. Na interação com os diversos Ministérios e instituições envolvidos no referido plano, firmou-se o âmbito de atuação regional e, em seguida, passou-se à definição do POR-Centro. Neste, as áreas de investimento foram definidas em função do cumprimento do plano de ação estabelecido. Depois de definidas as tipologias de ação, foram definidos os indicadores do sistema de monitorização. Em seguida, realizou-se a dotação financeira e depois os apoios. Os recursos deste Programa são uma fatia pequena do conjunto nacional. De cerca de 20 mil milhões (ou bilhões) de euros, a região centro vai gerir 2,1. Estes recursos regionais são então somados aos recursos nacionais ${ }^{72}$.

Ainda segundo Rodrigues ${ }^{73}$, a mudança paradigmática recente foi abismal na região Centro. “Até à década de 90, o planejamento estava na esfera das cabeças iluminadas, dos políticos, do meio acadêmico", e o trabalho de planejamento era recorrentemente feito por consultores ${ }^{74}$. No atual período, atores setoriais destacados, como as três Universidades da região, os sete institutos politécnicos, as incubadoras, os parques de ciência e tecnologia, as comunidades intermunicipais prepararam documentos conjuntos, por meio de reuniões, debates e workshops, o que ocorreu em diversos domínios, por exemplo, na educação, saúde, turismo, transportes. Este processo de definição da estratégia regional foi um mix das abordagens top-down e bottom up. Em suma, o posicionamento da região e a agenda temática, foram definidos pela CCDR, e o levantamento das ações necessárias para atingir esse posicionamento foi feito pelos stakeholders. Houve grande envolvimento local. Cerca de 700 pessoas, 300 entidades da região, estiveram envolvidas com a elaboração deste documento de cerca de duas mil páginas, desde associações empresariais a entidades de apoio social. A participação destas últimas aliás foi especialmente valorizada - pois este é um tema comunitário de destaque no Quadro atual, e a CCDR não tem experiência de atuação nesta área ${ }^{75}$.

Outro exemplo relevante neste sentido foi a participação do Cluster do Habitat. No âmbito da política nacional de clusterização, há clusters importantes na região Centro, um desses é o Cluster do Habitat ${ }^{76}$. Com um “[...] player tão importante como esse na região, não íamos ser nós a liderar esse processo sobre o qual não dominávamos a maior parte das matérias, e portanto,

\footnotetext{
${ }^{72}$ RODRIGUES, ibid.

${ }^{73}$ Idem, ibid.

${ }^{74}$ Assim como é comum que as empresas contratem consultores para a elaboração de projetos, como foi relatado em Encontro público organizado pela CCDR-Algarve com representantes da sociedade civil, "Made in Algarve - Turismo no Horizonte 2014-2020", realizado no dia 28/02/2014, em Albufeira.

${ }^{75}$ Idem, ibid.

${ }^{76}$ Sobre o tema, ver: [http://www.centrohabitat.net/pt], [http://portugalclusters.pt/membros/], [http://healthportugal.com/Quempor cento20somos/eec-qren].
} 
pedimos ao cluster que gerisse, no fundo, as reuniões. Nós convidamos vários atores, e o pivô era uma entidade externa." 77 Com base nesse amplo processo, conseguiu-se uma capacidade argumentativa em relação ao Governo central que não era tão forte como no passado. "É uma guerra com batalhas, umas se ganham, outras se perdem, e houve batalhas que perdemos, embora não perdemos nenhuma das cruciais." 78

É interessante notar como há perspectivas diferenciadas sobre a essência das ações de desenvolvimento regional. Alguns ressaltam a importância da concentração dos investimentos nas maiores cidades do país, com seus alegados efeitos de spillover; outros afirmam a importância dos espaços menos privilegiados, com destaque para o deserto interior; e outros, ainda, como Neves (2014), ressaltam a importância da mobilidade entre o interior e os centros (como um estímulo à manutenção das pessoas nas pequenas cidades).

Apesar do grande debate e dos avanços recentes na elaboração do novo Quadro, um olhar mais crítico aponta que a capacidade de intervenção das CCDRs no plano político regional é notadamente pequena, tendo em vista a falta do nível intermédio de governo e a ausência de regiões continentais com legitimidade democrática ${ }^{79}$.

Se o continente continua sob uma gestão centralizada, ainda que desconcentrada, as Regiões Autônomas ganharam um real espaço na definição das políticas regionais, com grande avanço no sentido de progressiva autonomização. Estas regiões foram ganhando competências e hoje têm responsabilidade plena sobre a gestão e implementação dos seus programas regionais. Tais PORs inicialmente eram parte dos programas nacionais; em seguida, ficaram restritos à áreas limitadas; e agora são programas regionais completos, em todas as áreas de intervenção ${ }^{80}$. No processo negocial com a Comissão, nota-se pequena diferença. Nas negociações com o governo português, em muitos casos, os representantes das RAs estão presentes e, de fato, estas regiões têm mais autonomia decisória em relação aos seus Programas ${ }^{81}$. As RAs realizaram grande percurso de evolução com governos e Parlamentos próprios, onde a discussão política é relevante. Estas aprovam seus orçamentos e planos de desenvolvimento a médio prazo, o que facilitou o processo de consolidação de capacidade interna na região de pensamento e de ação estratégica. Este é um elemento de grande diferenciação em relação ao continente, onde não existe este conjunto de

\footnotetext{
${ }^{77}$ Idem, ibid.

${ }^{78}$ Idem, ibid.

${ }^{79}$ FEIO, ibid.

${ }^{80}$ Idem, ibid.

${ }^{81}$ ROZSA, ibid.
} 
instituições regionais solidificadas e há eterna luta por manter funções que não estão suficientemente consolidadas no nível jurídico-legal ${ }^{82}$.

Botelho e Brito ${ }^{83}$ explicam que eles quase que fazem " $[\ldots]$ mini acordos de parceria com a Comissão", com uma autonomia muito maior para identificar suas necessidades dentro das regras e dos regulamentos comunitários. Estas duas RAs ainda recebem os benefícios europeus destinados às Regiões Ultraperiféricas (RUPs), em função da distância que se encontram dos centros europeus e consequentemente de seus custos econômicos aumentados.

$\mathrm{Na}$ literatura, são apresentados casos relevantes em que a Parceria tornou-se uma fonte de disputa política, com o governo nacional desafiado por atores regionais e locais. Dentre os atores subnacionais mais atuantes neste âmbito estão os que discordam das autoridades nacionais, por razões político-partidárias ou legais (constitucionais) ${ }^{84}$. Tal dinâmica aparece claramente, em Portugal, no caso da Madeira. Jardim, além de Presidente do PSD-Madeira há décadas, tem sido muito atuante no âmbito do CoR. Em entrevista pública, ele relata alguns conflitos com o governo central e chega a mencionar a possibilidade de a região se separar de Portugal e tornar-se um pequeno Estado independente, como Cingapura ${ }^{85}$.

Assim, em certo aspecto, a parceria estimulou esta concorrência entre os níveis nacional e subnacional, com a Comissão frequentemente fazendo o papel de mediadora, o que desestimulou os que a valorizavam como um mecanismo de eficiência, solidariedade ou de governação cooperativa ${ }^{86}$. Martins ${ }^{87}$, a propósito, destaca o caráter ambíguo da Comissão em relação à parceria. Esta, por vezes, é acusada de refutar as questões identitárias; por outras, de incentivá-las.

Por outro lado, na ótica dos que vêem a parceria como um veículo para a democratização das sociedades europeias, o resultado tem sido muito satisfatório em relação ao aumento da atividade entre diversos atores subnacionais e a disputa democrática em termos de concepções políticas. Uma das razões por que as autoridades regionais e locais aderiram à parceria foi o grande aumento de sua visibilidade em relação ao governo nacional e ao público ${ }^{88}$.

No tocante à sociedade civil portuguesa, esta ainda participa pouco, no contexto do destacado défice em termos de participação política ${ }^{89}$. A participação eleitoral em Portugal, nas

\footnotetext{
${ }^{82}$ FEIO, ibid.

${ }^{83}$ Ibid.

${ }^{84}$ HOOGHE, Liesbet. EU Cohesion Policy and Competing Models of European Capitalism. Journal of Common Market Studies, Vol. 36, n. 4 (december) (1998), p. 457-77.

${ }^{85}$ Essas e outras estórias de Jardim podem ser vistas na "grande entrevista" disponível no site do Governo da Madeira: [http://pgram.gov-madeira.pt]. Acesso em out, 2014.

${ }^{86}$ HOOGHE, ibid.

${ }^{87}$ MARTINS, Estevão de Rezende. Cultura e Poder. 2a ed. São Paulo: Saraiva, 2007.

${ }^{88}$ HOOGHE, ibid.

${ }^{89}$ MAGONE, José M. The quality of Portuguese Democracy in the European Union. Paper presented at the First
} 
eleições legislativas, passou de 84 por cento (em 1976) para 58 por cento (em 2011). Dinâmica semelhante ocorreu nas eleições para o Parlamento Europeu, em que a participação eleitoral é tradicionalmente menor, passou de 49,7 por cento (em 1989) para 36,8 por cento (em 2009) ${ }^{90}$.

Em relação à política de coesão, o diálogo avançou, mas as vozes locais mais relevantes foram as dos Representantes municipais e dos stakeholders setoriais, em detrimento de uma representação social mais ampla. As autoridades subnacionais conseguiram certa influência nos resultados, via PORs regionais, e ampliaram sua capacidade de mobilização, exercendo o lobby nas diversas instituições, nacionais e europeias ${ }^{91}$, mas ainda têm poder político pequeno se comparado ao governo central. As RAs, como referido, ganharam autonomia plena em relação aos seus programas regionais, mas estes representam reduzida parcela do total dos Fundos Estruturais. No conjunto, então, esta dinâmica pode ser caracterizada como uma forma de governação multinível assimétrica.

Por fim, muitos afirmam que a sociedade civil não participa pois não tem interesse. Se é verdade que os temas políticos pouco interessavam à sociedade portuguesa, essa realidade definitivamente mudou com a crise. No Portugal contemporâneo, o debate sobre os caminhos políticos e econômicos do país é uma constante na imprensa, nas Universidades e nas ruas. As pessoas comuns podem até não ter interesse específico em discutir meandros burocráticos do complexo funcionamento do sistema europeu ${ }^{92}$, mas é certo que elas se interessam pelo que as afeta diretamente. E como a crise impactou significativamente a qualidade de vida das famílias, são diversas as manifestações das organizações sociais ${ }^{93}$. Talvez se possa afirmar que isso ocorre de forma mais destacada nos maiores centros urbanos e corresponda a uma elite cultural. De fato, manifestações contundentes podem conviver com a apatia. No entanto, o relevante aqui é destacar que hoje há uma grande pressão sobre o governo português a respeito da condução desses processos, em especial da gestão dos Fundos Europeus. Um elemento que dificulta a passagem desta vociferação difusa para mecanismos concretos de participação cidadã é a distância que se

\footnotetext{
Conference of Portuguese Democracy, November (2004). Disponível em: [http://www.25abril.org/docs/congresso/democracia/02.14Jose\%20Magone_THE\%20QUALITY\%20OF\%20PORTUGUESE\%20DEMOCRACY\%20IN\%20THE\%20EUROP EAN\%20UNION.pdf]. Acesso em: 10 Out. 2013.

${ }^{90}$ LOBO, Marina Costa. Uma cidadania política, mas pouco. In: LOBO, Marina C (coord.). Portugal e a Europa: novas cidadanias. Lisboa: Fundação Francisco Manuel dos Santos e União Europeia (2013). Ainda assim, Lobo (ibid.) torna o tema mais complexo, tendo em vista que alguns estudos apontam a "vitalidade de uma parte minoritária de cidadãos politicamente ativos". A autora aponta a existência de duas visões diferentes sobre o tema, uma mais otimista e outra menos.

${ }^{91}$ PESSOA, ibid.

${ }^{92}$ Até porque, como desabafou a Prof ${ }^{a}$ Maria Manuel Leitão Marques da Universidade de Coimbra, muitos destes Regulamentos são "ilegíveis, incompreensíveis". Palestra proferida pela Prof a no Ciclo de Debates "Portugal e a União Europeia”, realizado no ISCSP-Universidade de Lisboa, no dia 18 Mar. 2014.

${ }^{93}$ Para uma visão mais ampla das manifestações contrária à atuação da Troika no país, ver Lobo (2013).
} 
sente da possibilidade real de interferir neste sistema complexo e pouco conhecido ${ }^{94}$, que foi dominado pela dinâmica tradicional da política partidária interna e é ainda pouco transparente. Em sentido amplo, este é um dos grandes desafios atuais da democracia.

No caso português, em comparação com a Espanha, no momento da adesão, as questões internacionais tinham menor visibilidade pública ${ }^{95}$, reforçando as teses do consenso passivo, da visão da Europa como uma construção das elites e da menor politização das questões europeias (refletida na convergência partidária sobre o tema). Ainda assim, neste período inicial, os portugueses eram considerados grandes entusiastas do projeto europeu e reconheciam grandes benefícios na integração lusa. Pridham ${ }^{96}$ destaca a mudança da orientação popular portuguesa em relação à Europa - a compreendendo como uma fator que contribuía para o desenvolvimento. Neste sentido, afirma que "o desempenho eficaz do governo encorajou um apoio crescente à democracia", ressaltando a tese da legitimidade pelo output. Lobo ${ }^{97}$ caracteriza esse apoio à Europa como instrumental e também "um pouco vazio", em função do desconhecimento sobre o funcionamento institucional e a significativa abstenção eleitoral.

Este apoio instrumental está, nesse momento, em queda ${ }^{98}$, em consequência da continuada crise econômica nacional, que tem levado à deterioração do apoio dos portugueses às instituições políticas, tanto em nível nacional como europeu, com o agravamento do quadro de insatisfação com a democracia, da falta de identificação com os partidos políticos e da abstenção eleitoral ${ }^{99}$. Esta se reduziu ainda mais nas eleições do PE de $2014{ }^{100}$.

\footnotetext{
${ }^{94}$ Também segundo Pridham (2005), a sociedade civil "não se relaciona facilmente com a integração europeia devido ao sentimento de distância (psicológica, assim como política) de Bruxelas."

${ }^{95}$ PRIDHAM, ibid.

${ }^{96}$ Idem, ibid.

${ }^{97}$ Ibid.

${ }^{98}$ Recentes sondagens do Eurobarômetro confirmam essa perspectiva de gradual descontentamento dos cidadãos em relação à UE. Ver: CAMISÃO, Isabel. Dilemas de Liderança e Legitimidade na UE: entre pragmatismo e inspiração. In: RIBEIRO, Maria Manuela T; VALENTE, Isabel F e RIBEIRO, Ana M. R. (coords). Europa: que futuro? Olhares portugueses. Coimbra: CIEDA (2012). Cf. Eurobarômetro 76, "Public Opinion in the European Union", Dezembro de 2011 , p. 22.

${ }^{99}$ LOBO, ibid., p. 82

${ }^{100}$ Ver: [http://www.resultados-eleicoes2014.eu/pt/country-results-pt-2014.html\#table01]. A propósito, o debate social sobre a eleições europeias em Portugal foi quase nulo, ficando restrito à negociações partidárias. Espantosamente, não houve nenhum debate, nem cobertura na televisão aberta portuguesa. As televisões públicas assim o fizeram como protesto. "Os Diretores de informação da RTP, SIC e TVI rejeitam uma lei que determina que o Estado decida quem deve ser entrevistado, quem deve participar em debates, e o que deve ser notícia”. Segundo estes, "o enquadramento legislativo relativo à atividade dos órgãos de comunicação social em período eleitoral é desajustado, confuso e interfere, de forma inaceitável, na liberdade editorial", ferindo a liberdade de informação. Disponível em: [http://www.publico.pt/politica/noticia/parlamento-discute-mudancas-na-cobertura-de-eleicoes-directores-deinformacao-da-rtp-sic-e-tvi-rejeitam-iniciativas-1628007] Acesso em: 12 Mar. 2014.
} 


\section{Conclusão}

Nas últimas décadas, Portugal alcançou um nível elevado de IDH e tornou-se uma democracia plena. A via da integração europeia consolidou-se como um projeto de Estado, e os avanços políticos estimulados pelos padrões europeus foram relevantes. A Política europeia de Coesão Econômica, Social e Territorial (PCEST) provocou a criação de novas estruturas de gestão, dinâmicas de grande capacitação institucional e de construção de planejamentos estratégicos, tornando-se equivalente à política portuguesa de desenvolvimento regional.

Por outro lado, destacaram-se persistentes problemas políticos, como o baixo nível de controle (accountability) e a total falta de transparência do processo negocial, contribuindo para a obscuridade do processo político europeu. Houve também dificuldades de implementação da PCEST em Portugal. Como os recursos foram distribuídos, em princípio, seguindo a lógica interna já estabelecida - por meio do FEF, Fundo de Equilíbrio Financeiro, o que passou a ser chamado de fefização - alguns municípios receberam verbas avultadas, maiores que as provenientes do governo central e, algumas vezes, as utilizaram em projetos ornamentais, com baixo impacto na dinâmica de desenvolvimento socioeconômico e de custosa manutenção local, o que por vezes tornou-se inviável. A reduzida capacidade de visão estratégica nas municipalidades também constituiu-se em um elemento dificultador. Não obstante, a PCEST tem estimulado a participação dos stakeholders setoriais no desenho e implementação dos Programas Operacionais Regionais (PORs), e evidenciou-se também a força dos Representantes locais na concretização de projetos específicos, o que confirma a hipótese da importância fundamental das lideranças na maior ou menor projeção política local.

O processo político-histórico de tendência descentralizante, relacionado com a necessidade de maior legitimação, informação e recursos locais ${ }^{101}$, assim como os questionamentos relativos ao défice democrático da UE foram impulsos centrais para a construção dos mecanismos de Governança Multinível. A mudança tem ocorrido de forma gradual. A força restritiva do framework europeu revelou-se quando os agentes locais tinham objetivos muito distintos dos parâmetros estabelecidos e na definição, mais recentemente, de prioridades negativas (como tem sido o caso dos investimentos lusos em infraestruturas). A ênfase passou a ser mais em áreas soft, como competitividade e inovação. O processo negocial da Comissão com o Governo Português envolveu interlocução ampla, construção de consensos e aprendizado conjunto.

${ }^{101}$ PIATTONI, ibid. 
O diálogo avançou, apesar de ainda haver uma limitada representação social. As autoridades subnacionais ampliaram sua capacidade de mobilização. Mesmo sem Escritórios Regionais em Bruxelas (dinâmica influenciada pela situação de Estado Unitário), os Representantes locais exerceram o lobby na Representação da Comissão em Lisboa e nas instituições nacionais. Nem sempre desafiaram o Governo Central, é verdade, na maior parte das vezes agiram em paralelo nestas duas instâncias. O processo de empoderamento regional é de mais difícil comprovação no continente, mas ocorreu nas RAs com ganhos crescentes de autonomia em relação aos seus programas regionais. Ainda assim, estes atores dispuseram de poder decisório reduzido, se comparados ao governo central, tendo em vista a menor dimensão dos PORs (Programas Operacionais Regionais) diante do montante total dos investimentos dos Fundos. Também em relação à Comissão Europeia, as competências foram parcialmente partilhadas entre esta e o governo português. A participação influente da Comissão ficou restrita à fase inicial da PCSET (no tocante às definições estratégicas e programáticas), enquanto o governo português dispôs de uma atuação ampla em todas as fases, assumindo a responsabilidade pela definição dos projetos (seleção, aprovação e monitoramento) e dos parceiros. No conjunto, então, podemos caracterizar esta dinâmica como uma forma de governança multinível assimétrica.

\section{Bibliografia}

BACHTLER, John e MENDEZ, Carlos - Who Governs EU Cohesion Policy? Deconstructing the Reforms of the Structural Funds. JCMS 2007, v 45, n. 3 (2007) p. 535-564.

CAMISÃO, Isabel - Dilemas de Liderança e Legitimidade na UE: entre pragmatismo e inspiração. In: RIBEIRO, Maria Manuela Tavares; VALENTE, Isabel Maria Freitas; RIBEIRO, Ana Maria Reis (coords). Europa: que futuro? Olhares portugueses. Coimbra: CIEDA/CEIS20, 2012.

Comissão Europeia - Livro Branco sobre a Governança Europeia. Bruxelas: Comissão Europeia, 2001.

FERNANDES, Antonio Teixeira - Descentralização e Teoria do Estado. IN Actas Colóquio sobre La Déscentralisation: Évaluation d'um Thème de Recherches. Universidade de Orléans, 1 e 2 de Out., 1987. Disponível em: [http://repositorio-aberto.up.pt/bitstream/10216/8949/2/1690.pdf].

GUEDES, Nuno - Convergência ideológica? Uma análise comparada dos programas eleitorais do 
PS e do PSD (1991-2009). Sociologia, Problemas e Práticas, Lisboa, no 68 (2012) pp. 103-125.

HAAS, Ernst B. - Does Constructivism subsume neo-functionalism? In: CHRISTIANSEN, Thomas. Social Construction of Europe. UK: Sage Publications (2001), pp. 100-123.

HOOGHE, Liesbet. EU Cohesion Policy and Competing Models of European Capitalism. Journal of Common Market Studies, Vol. 36, n. 4 (december) (1998), pp. 457-77.

LOBO, Marina, Costa - Uma cidadania política, mas pouco. In: LOBO, Marina Costa (coord.). Portugal e a Europa: novas cidadanias. Lisboa: Fundação Francisco Manuel dos Santos e União Europeia, 2013.

MAGONE, José M. The quality of Portuguese Democracy in the European Union. Paper presented at the First Conference of Portuguese Democracy, November (2004). Disponível em: [http://www.25abril.org/docs/congresso/democracia/02.14-

Jose\%20Magone_THE\%20QUALITY\%20OF\%20PORTUGUESE\%20DEMOCRACY\%20IN\%20 THE\%20EUROPEAN\%20UNION.pdf. Acesso em: 10 Out. 2013.

MARKS, Gary. Structural Policy and Multilevel Governance in the EC. In: CAFRUNY, Alan and ROSENTHAL, Glenda (eds.). The State of the European Community. Boulder: Lynne Rienner, 1993.

MARKS, Gary. Exploring and Explaining Variation in EU Cohesion Policy. In: HOOGHE, Liesbet (ed). Cohesion Policy and European Integration: Building Multilevel Governance. Oxford: Oxford University Press, (1996), pp. 388-422,.

MARTINS, Estevão de Rezende. - Cultura e Poder. $2^{\mathrm{a}}$ ed. São Paulo: Saraiva, 2007.

MATEUS, Augusto - 25 Anos de Portugal Europeu: A economia, a sociedade e os fundos estruturais. Lisboa: Fundação Francisco Manuel dos Santos, 2013.

MEDEIROS, Eduardo. A Política de Coesão da União Europeia em Portugal (1989-2013): contribuições para o desenvolvimento territorial. In: Centro de Estudos Geográficos da Universidade de Lisboa (CEG), Instituto de Geografia e Ordenamento do Território (IGOT), 
Lisboa, 21/08/2013. Disponível em:

[http://ww3.fl.ul.pt/pessoais/Eduardo_Medeiros/docs/PC_EM_21_08_2013.pdf]. Acesso em: Jan 2014.

Ministério dos Negócios Estrangeiros - Informação Estatítica.União Europeia, Estados-membros. Lisboa: DGAE, MNE, dez. 2013.

MOZZICAFREDDO, Juan - La decentralisation administrative et les innovations en matiére de politiques regionales au Portugal. Sociologia, Problemas E Práticas, Lisboa, n. 41, (2003), p. 151179.

OLIVEIRA, Luís Valente de - A Regionalização em Portugal. In: COSTA, J. S. e NIJKAMP, P. (coord.). Compêndio de economia regional: volume 1: teoria, temáticas e políticas. Cascais: Principia, 2013.

PIATTONI, Simona - The theory of multi-level governance: conceptual, empirical and normative challenges. Oxford: Oxford University Press, 2010.

PRIDHAM, Geoffrey - A integração europeia e a consolidação democrática da Europa do sul. In: PINTO, António Costa e TEIXEIRA, Nuno Severiano (org.) A Europa do Sul e a construção da União Europeia (1945-2000). Lisboa: Universidade de Lisboa, Instituto de Ciências Sociais, 2005.

QREN - Quadro de Referência Estratégico Nacional, 2007-2013. Lisboa: Ed. Observatório do QCA III, 2007. Disponível em: [www.qren.pt]. Acesso em: Fev, 2013.

ROSENAU, James N. - Governance, Order and Change in World Politics. In: ROSENAU, James N.; CZEMPIEL, Ernst, O. (ed.), Governance without Government. Order and Change in World Politics. Cambridge: Cambridge University Press (1992) p. 1-29.

SANTOS, Boaventura de Sousa - Portugal. Ensaio contra a auto-flagelação. $2^{\mathrm{a}}$ ed. Coimbra: Ed. Almedina, 2012. 